\title{
Passive Lossless Snubbers for DC/DC Converters
}

\author{
Ching-Jung Tseng Chern-Lin Chen \\ Power Electronics Laboratory \\ Department of Electrical Engineering \\ National Taiwan University \\ Taipei, Taiwan
}

\begin{abstract}
Passive lossless snubbers are proposed to improve the turn-on and turn-off transients of the MOSFET's in PWM dc/dc converters. Switching losses and EMI noises are reduced by restricting di/dt of the reverse recovery current and $\mathrm{dv} / \mathrm{dt}$ of drain-source voltage. The MOSFET operates at ZVS turn-off and near ZCS turn-on. The freewheeling diode is also commutated with ZVS. To be a demonstration, operation principles, theoretical analyses, relevant equations and experimental results of a boost converter equipped with the proposed snubber are presented in detail. Efficiency of $96 \%$ has also been measured in the experimental results reported for a $1 \mathrm{~kW}, 100 \mathrm{kHz}$ prototype in the laboratory. Six basic nonisolated PWM dc/dc converters ( buck, boost, buck-boost, Cúk, Sepic and Zeta ) equipped with the proposed passive lossless snubbers are also shown in this paper.
\end{abstract}

\section{INTRODUCTION}

Pulse width modulated (PWM) dc/dc converters have been widely used as switched mode power supplies in industrics. The PWM technique is praised for its high power capability and ease of control. Higher power density and faster transient response of PWM dc/dc converters can be achicved by increasing the switching frequency. However, as the switching frequency increases, so do the switching losses and EMI noiscs. High switching losses reduce the power capabilities while serious EMI noises interfere the control of PWM dc/dc converters.

Switching losses and EMI noises of PWM dc/dc converters are mainly generated during turn-on and turn-off switching transients. According to [1], there are three different non-ideal commutation phenomena when MOSFET's are used as power switches:

1. A surge current flows through the MOSFET caused by the reverse recovery current of the freewheeling diode during turn-on process. This is the dominant part of switching losses and the di/dt EMI noise source.

2. Discharge of the parasitic drain-source capacitance of the MOSFET during turn-on process. This mechanism can be reduced only by resonant converter techniques or active snubbers.
3. Fast increase of the drain-source voltage during turn-off process. This is the source of dv/dt EMI noise and turnoff loss.

To improve the problems resulted from the non-ideal phenomena described above, several kinds of soft switching technologies are presented in literature [2-9]. Active snubbers as introduced in [2-5] can reduce all three loss mechanisms by using auxiliary switches. Unfortunately, an auxiliary switch increases the complexity of both the power circuit and the control circuit. Synchronization problems between control signals of two switches during transient also complicate the control strategy. Circuit cost is increased and reliability is decreased by using active snubbers. RCD snubbers have the simplest structures and hence lowest costs [6]. However, it also thas the worst performance since the switching losses are dissipated through resistors and thus reduce the efficiency of the circuit. Resonant converters commutate with either zero-voltage-switching (ZVS) or zero-current-switching (ZCS) to reduce switching losses [78]. However, conduction losses and current stresses are increased due to high circulating current involved. It is also hard to design EMI filter and control circuit because of a wide switching frequency range. Comparing with threc technologies discussed above, a passive lossless snubber can effectively restrict switching losses and EMI noises using no active components and no power dissipative components [9]. No additional control is needed and no circulating energy is generated. Circuit structure is as simple as RCD snubbers while circuit efficiency is as high as active snubbers and resonant converters. Low cost, high performance and high reliability are the distinct advantages of a passive lossless snubber.

To be a demonstration, a boost converter equipped with the proposed snubber is investigated in depth. Snubber operation principles are analyzed and the component parameters can be mathematically determined by the design rules presented. Experimental results of a $1 \mathrm{~kW}, 100 \mathrm{kHz}$ boost converter are reported to verify the analysis. Six basic PWM dc/dc converters equipped with the proposed snubbers are also illustrated in this paper. 


\section{A BOOST CONVERTER EQUIPPED WITH THE PASSIVE LOSSLESS SNUBBER}

\section{A. Principle of Operation}

Shown in Fig. 1 is a boost converter with the proposed passive lossless snubber, which is encircled by dotted lines. During turn-on process, injected charges in the low-doped middle region of diode $D_{1}$ cause transient reverse recovery current flowing reversely through diode $D_{1}$. The surge current is the major cause of the switching losses. Growth rate of the reverse recovery current is restricted by the snubber inductor Ls to suppress the switching loss. During turn-off process, drain-source voltage increases immediately to output voltage. Fast $\mathrm{dv} / \mathrm{dt}$ of drain-source voltage increases the turn-off loss, and of more importance, it generates serious EMI noises. Growth rate of drain-source voltage is restricted by the snubber capacitor $\mathrm{Cs}$ to obtain ZVS turn-off and to reduce EMI noises. Notice that the freewheeling diode is also commutated with ZVS during both turn-on and turn-off.

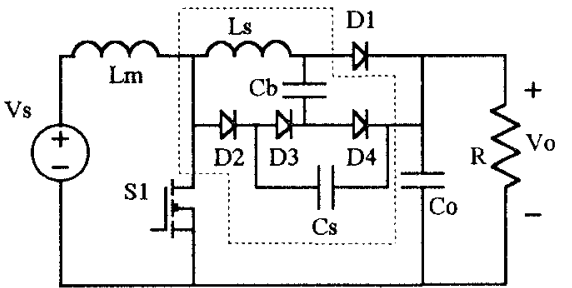

Fig. $1 \mathrm{~A}$ boost converter with the passive lossless snubber.

Turn-on and turn-off switching losses are reduced by the snubber inductor and the snubber capacitor, respectively. The energy transferred to the buffer capacitor $\mathrm{Cb}$ can be viewed as the summation of the energy absorbed in snubber inductor Ls and snubber capacitor Cs. Energy recovery is achieved by discharging the buffer capacitor $\mathrm{Cb}$ to the output. Ideally, the absorbed power is neither dissipated nor accumulated in the passive components of this snubber.

\section{B. Equivalent Circuit Analysis}

To analyze the steady state operations of the circuit shown in Fig. 1, following assumptions are made during one switching cycle:

(1). The output capacitor $\mathrm{C}_{0}$ is large enough to assume that the output voltage $V_{o}$ is constant and ripplefree.

(2). The input voltage $V_{\mathrm{s}}$ is constant.

(3). All semiconductor devices are ideal, except the freewheeling diode $\mathrm{D} 1$.

(4). The main inductor $\mathrm{Lm}$ is much greater than the snubber inductor Ls.
Based on these assumptions, circuit operations in one switching cycle can be divided into eight stages as shown in Fig. 2 (a)-(h), respectively.

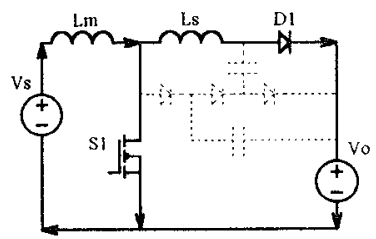

(a) Stage 1 ( $\mathrm{S}_{1}$ on)

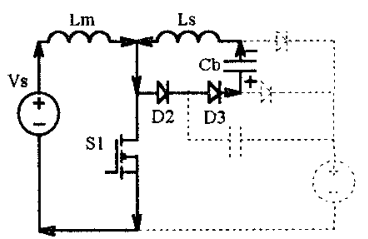

(c) Stage 3(D2 on)

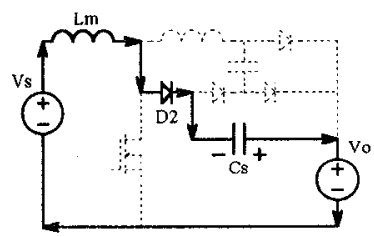

(e) Stage 5(S1 off, $D_{2}$ on)

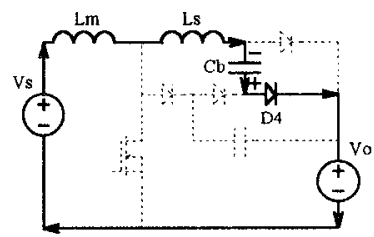

(g) Stage 7(D2, $\mathrm{D}_{3}$ off)

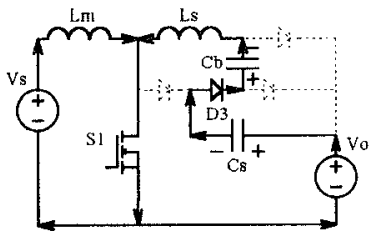

(b) Stage 2(D1 off, $D_{3}$ on)

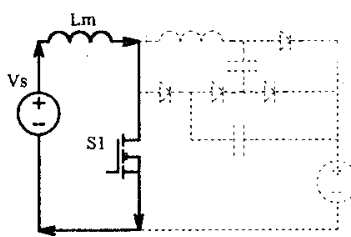

(d) Stage 4(D2, $\mathrm{D}_{3}$ off)

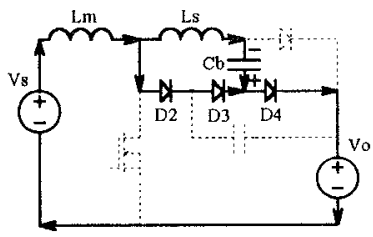

(f) Stage $6\left(D_{3}, D_{4}\right.$ on $)$

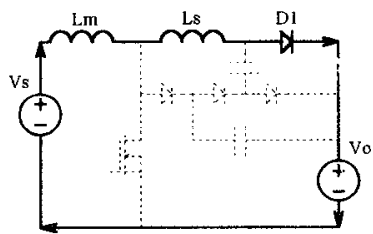

(h) Stage 8 (Di on, D6 off)
Fig 2. Equivalent circuits during one switching cycle

Stage 1 (Fig 2.a $;$ to $<\mathrm{t}<\mathrm{t} 1$ ):

The switch $S_{1}$ turns on at to. During turn-on process, freewheeling diode $D_{1}$ is not immediately turned off because of the reverse recovery phenomenon. Growth rate of the drain current is restricted by the snubber inductor to softly turn on the MOSFET. Current of the snubber inductor Ls is given by

$I_{L s}(t)=I_{F}\left(t_{0}\right)-\frac{V_{O}}{L_{S}}\left(t-t_{0}\right)$

where $\operatorname{IF}(\mathrm{t})$ is the forward current flowing from the input.

Stage 2 ( Fig $2 . \mathrm{b} ; \mathrm{t} 1<\mathrm{t}<\mathrm{t} 2$ ):

The reverse recovery phenomenon finishes at $t 1$. As soon as $\mathrm{D}_{1}$ is turned off, diode $\mathrm{D}_{3}$ is naturally turned on because VCs and $\mathrm{VCb}$ are equal to zero. Snubber 
inductor Ls, snubber capacitor $\mathrm{Cs}_{s}$ and buffer capacitor $\mathrm{Cb}$ are charged by the output through the first resonant path $V_{o}-C_{s}-D_{3}-C_{b}-L_{s}-S_{1}$. Growth rate of the voltage across $\mathrm{Dl}$, which is equal to $\mathrm{VCs}+\mathrm{Vcb}$, is restricted to achieve ZVS turn-off of freewheeling diode $\mathrm{D} 1$. Snubber inductor current, snubber capacitor voltage and buffer capacitor voltage are:

$I_{L s}(t)=-\frac{V_{O}}{Z_{1}} \sin \left(\omega_{1}\left(t-t_{1}\right)\right)-I_{r} \cos \left(\omega_{1}\left(t-t_{1}\right)\right)$

$V(t)=I_{r} Z_{1} \sin \left(\omega_{1}\left(t-t_{1}\right)-V_{o} \cos \left(\omega_{1}\left(t-t_{1}\right)\right)+V_{o}\right.$

$V_{C s}(t)=\frac{C_{b}}{C_{S}+C_{b}} V(t), \quad V_{C b}(t)=\frac{C_{S}}{C_{S}+C_{b}} V(t)$

where

$I_{r r}=\frac{V_{O}}{L_{S}}\left(t_{1}-t_{0}\right)-I_{F}\left(t_{0}\right)$

$Z_{1}=\sqrt{\frac{L_{s}\left(C_{S}+C_{b}\right)}{C_{s} C_{b}}}$

$\omega_{1}=\sqrt{\frac{C_{S}+C_{b}}{L_{S} C_{S} C_{b}}}$

Peak value of the drain current of switch $S_{1}$ is obtained by the summation of forward current IF and peak snubber inductor current ILs,p. The peak value appears when $\mathrm{VCb}+\mathrm{VCs}_{\mathrm{C}}$ is equal to $\mathrm{V}_{\mathrm{o}}$, and it is given by

$I_{L s, p}=\frac{\sqrt{V_{O}^{2}+\left(I_{m} Z_{1}\right)^{2}}}{Z_{1}}$

The first resonance stops at $t_{2}$ when $\mathrm{VCs}_{\mathrm{C}}(\mathrm{t} 2)$ equals $\mathrm{V}_{\mathrm{o}}$ because diode $\mathrm{D}_{2}$ is turned on. By using reciprocity theorem, snubber inductor current at 22 is given by

$I_{L s}\left(t_{2}\right)=\frac{\sqrt{\left(I_{m} Z_{1}\right)^{2}+V_{o}^{2}-\left(V_{o} \frac{\mathcal{C}_{S}}{C_{\mathrm{b}}}\right)^{2}}}{Z_{1}}$

From (9), the energy stored in $\mathrm{Ls}$ and $\mathrm{Cs}$ can be given by

$$
\begin{aligned}
& E_{L s}\left(t_{2}\right)+E_{C b}\left(t_{2}\right)=\frac{1}{2} L_{S} I_{L s}{ }^{2}\left(t_{2}\right)+\frac{1}{2} C_{b} V_{C b}{ }^{2}\left(t_{2}\right) \\
& =\frac{1}{2} L_{S} I_{r r}{ }^{2}+\frac{1}{2} C_{S} V_{O}{ }^{2}
\end{aligned}
$$

Stage 3 ( Fig 2.c; $\mathrm{t} 2<\mathrm{t}<\mathrm{t} 3$ ):

After VCs is charged to output voltage $V_{o}$ at $t 2, D_{2}$ is turned on and VCs keeps constant. The current in Ls starts to charge $\mathrm{Cb}$ through the second resonant path $\mathrm{L}_{s}-\mathrm{D}_{2}-\mathrm{D}_{3}-\mathrm{Cb}$. $\mathrm{Ls}$ and $\mathrm{Cb}$ are performing one-way resonance because of diode $\mathrm{D}_{2}$ and $\mathrm{D}_{3}$. The current through $\mathrm{Ls}$ and the voltage across $\mathrm{Cb}$ are given by

$$
\begin{aligned}
& I_{L s}(t)=\frac{C_{S}}{C_{b}} \frac{V_{C}}{Z_{2}} \sin \left(\omega_{2}\left(t-t_{2}\right)\right)-I_{S 2} \cos \left(\omega_{2}\left(t-t_{2}\right)\right) \\
& V_{C b}(t)=I_{S 2} Z_{2} \sin \left(\omega_{2}\left(t-t_{2}\right)\right)+\frac{C_{S}}{C_{b}} V_{O} \cos \left(\omega_{2}\left(t-t_{2}\right)\right)
\end{aligned}
$$

where

$$
\begin{aligned}
& I_{S 2}=\frac{V_{O}}{Z_{1}} \sin \left(\omega_{1}\left(t_{2}-t_{1}\right)\right)+I_{r r} \cos \left(\omega_{1}\left(t_{2}-t_{1}\right)\right) \\
& Z_{2}=\sqrt{\frac{L_{S}}{C_{b}}} \\
& \omega_{2}=\sqrt{\frac{1}{L_{S} C_{b}}}
\end{aligned}
$$

The second resonance stops at $\mathrm{t} 3$ when ILs(t3) equals zero. Since the energy in $L_{s}$ is completely transferred to $\mathrm{Cb}$ in this stage, the energy stored in $\mathrm{Cb}$ at $\mathrm{t} 3$ can be found following (10) to be

$$
\begin{aligned}
& \frac{1}{2} C_{b} V_{C b}{ }^{2}\left(t_{3}\right)=E_{C b(13)}=E_{L s(t 2)}+E_{C b(12)} \\
& =\frac{1}{2} L_{S} I_{r r}{ }^{2}+\frac{1}{2} C_{s} V_{O}{ }^{2}
\end{aligned}
$$

Also, the peak voltage of the buffer capacitor $\mathrm{Vcb}_{\mathrm{p}, \mathrm{p}}$ is given by

$$
V_{C b, p}=V_{C b}\left(t_{3}\right)=\sqrt{\frac{L_{S} I_{r r}^{2}+C_{S} V_{o}{ }^{2}}{C_{b}}}
$$

It also determines the voltage stress of freewheeling diode, which is equal to $V_{o}$ plus $V_{C b}, p$.

Stage 4 ( Fig 2.d $; \mathrm{t} 3<\mathrm{t}<\mathrm{t} 4$ ):

At $\mathrm{t} 3$, ILs is decreased to zero while $\mathrm{D}_{2}$ and $\mathrm{D}_{3}$ are turned off. The current through Ls keeps zero and the voltage across $\mathrm{Cb}_{b}$ keeps constant after t3. From (16), the total energy transferred to $\mathrm{Cb}$ can be viewed as the summation of the energy which were absorbed in Ls and $C_{s}$. The circuit operation in this stage is identical to the normal turn-off state of a conventional boost converter.

\section{Stage 5 ( Fig 2.e $; \mathrm{t}_{4}<\mathrm{t}<\mathrm{t} 5$ ):}

After the switch $S_{1}$ turns off at $t 4$, forward current $\operatorname{IF}(\mathrm{t} 4)$ flows through $\mathrm{D}_{2}$ to discharge $\mathrm{C}_{s}$ to the output. Diodes D3 and D4 are not turned on because they are reverse biased by VCs. Drain-source voltage of $S_{1}$ is equal to $V_{o}$. VCs. Slow dv/dt of drain-source voltage is obtained while $V_{C s}$ is discharged from $V_{0}$ to zero. 
Assuming that $\operatorname{Ir}(\mathrm{t})$ is constant during this stage, $\mathrm{VCs}$ is given by

$$
V_{C s}(t)=V_{O}-\frac{I_{F}\left(t_{4}\right)}{C_{S}}\left(t-t_{4}\right)
$$

Stage 6 (Fig 2.f ; t5 $<\mathrm{t}<\mathrm{t} 6$ ):

Diodes D3 and D4 are turned on by the forward current $\operatorname{IF}(\mathrm{ts})$ when VCs is discharged to zero at $t 5$. Voltage across $\mathrm{Ls}$ equals $\mathrm{VCb}$ and makes ILs increased to discharge $\mathrm{Cb}$ to output. Circuit operation is similar to the second resonance in stage 2. ILs and $\mathrm{VCb}$ are given by

$$
\begin{gathered}
I_{L s}(t)=\frac{V_{C b}\left(t_{2}\right)}{Z_{2}} \sin \left(\omega_{2}\left(t-t_{5}\right)\right) \\
V_{C b}(t)=V_{C b}\left(t_{2}\right) \cos \left(\omega_{2}\left(t-t_{5}\right)\right)
\end{gathered}
$$

Stage 7 ( Fig 2.g; $6<\mathrm{t}<\mathrm{t} 7$ ):

Inductor current ILs is increased to $\mathrm{IF}_{\mathrm{f}}(\mathrm{t} 6)$ at $\mathrm{t} 6, \mathrm{D}_{2}$ and D3 are turned off. After $t 6, \mathrm{IF}(\mathrm{t})$ discharges $\mathrm{Cb}$ to output through D4. ZVS turn-on of the diode $\mathrm{D}_{1}$ is achieved by slow $d v / d t$ of $\mathrm{Vcb}$. Assuming that $\operatorname{IF}(\mathrm{t})$ is constant in this stage, $\mathrm{VCb}$ is given by

$$
V_{C b}(t)=V_{C b}\left(t_{6}\right)-\frac{I_{F}\left(t_{6}\right)}{C_{b}}\left(t-t_{6}\right)
$$

Stage 8 ( Fig 2.h $; \mathrm{t} 7<\mathrm{t}<\mathrm{t}_{0}$ ):

Capacitor voltage $\mathrm{VCb}$ is discharged to zero at $\mathrm{t} 7 . \mathrm{D}_{4}$ is turned off and $D_{1}$ is turned on simultaneously. Snubber energy recovery process is accomplished when all energy in the buffer capacitor $\mathrm{Cb}$ is transferred to the output. After that, input current IF $(t)$ flows through Di instead of D4 to prevent $C_{s}$ from being charged reversely. Circuit operation will be the same as in stage 1 when the switch $S_{1}$ turns on again at to in the next switching cycle.

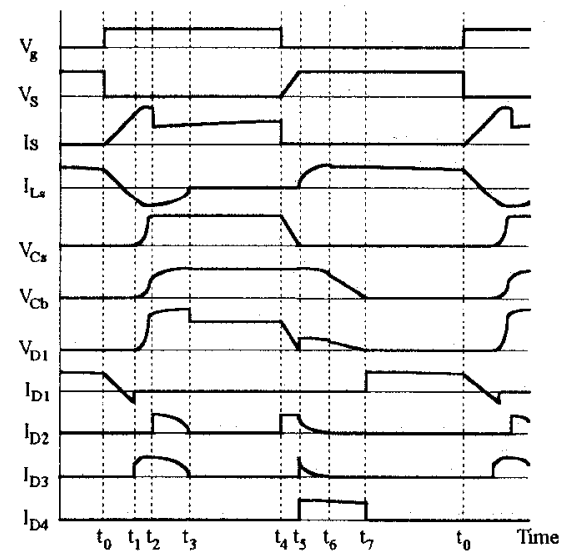

Fig 3. Key waveforms of the boost converter with the passive lossless snubber.

\section{Design Considerations}

The snubber inductor $\mathrm{Ls}$, snubber capacitor $\mathrm{Cs}$ and buffer capacitor $\mathrm{Cb}$ are the three main elements to be designed. Following rules should be noticed when designing $\mathrm{L}, \mathrm{C}$ values.

1. In stage 6, diodes $\mathrm{D}_{2}$ and $\mathrm{D} 3$ should be naturally turned off before the voltage of $\mathrm{Cb}$ is discharged to zero, or the residential current will turn on $\mathrm{D}_{2}, \mathrm{D}_{3}$ and $\mathrm{D}_{4}$ for the entire switching period. In other words, following inequality has to be obeyed :

$$
\frac{1}{2} L_{S} I_{p}^{2}<\frac{1}{2} L_{S} I_{r}^{2}+\frac{1}{2} C_{S} V_{O}^{2}
$$

It requires higher Irr or larger $C_{s}$.

2. Current stress of MOSFET and voltage stress of freewheeling diode are given in (8) and (17), respectively. Larger $\mathrm{Cs}_{s}$ results in higher MOSFET current stress and higher diode voltage stress.

3. According to (17), $\mathrm{Cb}$ has to be at least 16 times as $\mathrm{Cs}$ to limit VCb to $100 \mathrm{~V}$ with a $400 \mathrm{~V}$ output. Practically, $\mathrm{Cb}$ should be about 30 times as $\mathrm{Cs}_{\mathrm{s}}$ considering reverse recovery energy.

4. Snubber inductor Ls should be selected as large as possible to decrease reverse recovery loss. According to the following equation in [10], larger Ls results in lower Irr.

$$
I_{r r} \propto \sqrt{I_{F} \frac{d I_{F}}{d t}} \propto \sqrt{\frac{I_{F}}{L_{S}}}
$$

5. Resonant frequency in (15) should be much larger than switching frequency to ensure correct operation of the snubber cell.

Trade-offs have to be made when designing $\mathrm{L}_{s}, \mathrm{C}_{s}$ and $\mathrm{Cb}$. Voltage and current stresses of diode $\mathrm{D}_{2}, \mathrm{D}_{3}$ and $\mathrm{D} 4$ are equal to the output voltage and the input current. However, lower component ratings are also acceptable due to short snubber operating time. Voltage stress of $\mathrm{D}_{1}$ and current stress of MOSFET are increased by $\mathrm{VCb}, \mathrm{p}$ and ILs,p, respectively. Voltage stress of MOSFET and current stress of $D_{1}$ are the same as those without the snubber embedded.

\section{THE GENERAL SNUBBER CELL FOR DC/DC CONVERTERS}

The proposed snubber cell can be seen as the combination of a turn-on snubber cell and a turn-off snubber cell. The turn-on snubber, shown in Fig. 4(a), limits di/dt of the reverse recovery current by a snubber inductor in series 
with freewheeling diode. Two diodes and one capacitor are added to recover the absorbed energy to output. Most of the turn-off snubber proposed in literature use a snubber capacitor parallel to the switch to limit $\mathrm{dv} / \mathrm{dt}$ of drain-source voltage. However, in a switching circuit, the voltage across the freewheeling diode always varies with the drain-source voltage of the switch. In other words, $\mathrm{dv} / \mathrm{dt}$ of drain-source voltage can also be limited in the turn-off snubber, shown in Fig. 4(b), by paralleling a snubber capacitor to the diode. An additional diode is added to isolate the switch from the snubber capacitor [2]. The isolation can prevent the snubber capacitor from being discharged in the switch at light load and high line.

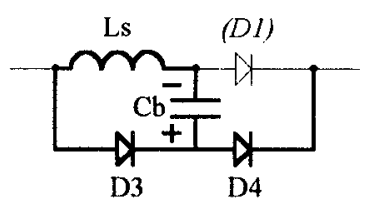

(a) turn-on snubber cell

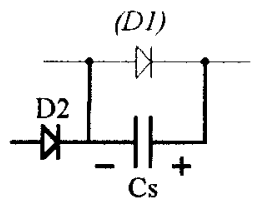

(b) turn-off snubber cell
Fig 4. General passive lossless tum-on and turn-off snubber cells

Combining the turn-on and turn-off snubber cells described above, the proposed passive lossless snubber cell for nonisolated PWM dc/dc converters is defined and shown in Fig. 5. Node $\boldsymbol{A}$ and $\boldsymbol{K}$ are connected to the anode and the cathode of the converter freewheeling diode $\mathrm{D}_{1}$, respectively. Node $\boldsymbol{A}^{\prime}$ is connected to the component which was connected to the anode of the freewheeling diode in the original circuit.

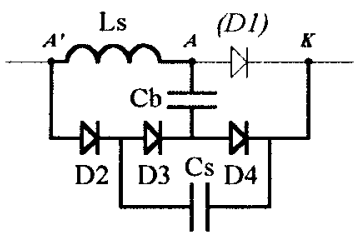

Fig 5. The general passive lossless snubber cell proposed for nonisolated PWM $\mathrm{dc} / \mathrm{dc}$ converters

The proposed general snubber cell consists of one inductor $\mathrm{Ls}$, two capacitors $\mathrm{Cs}_{\mathrm{s}}$ and $\mathrm{Cb}$ and three diodes $\mathrm{D}_{2}$, D3 and D4. The snubber inductor $L s$ is placed in series with the freewheeling diode $\mathrm{D}_{1}$. It is designed to restrict di/dt of the reverse recovery current to achieve ZCS turn-on. The snubber capacitor $C_{s}$ is placed in parallel with $D_{3}$ and $D_{4}$ and isolated by diode $\mathrm{D}_{2}$. $\mathrm{D}_{3}$ and $\mathrm{D}_{4}$ are freewheeling during turn-off. It is designed to restrict $\mathrm{dv} / \mathrm{dt}$ of drainsource voltage to achieve ZVS turn-off. ZVS turn-on and turn-off of freewheeling diode are also obtained. Switching losses and EMI noises during turn-on and turn-off are eliminated by the snubber cell. All energy absorbed in the snubber inductor and snubber capacitor are transferred to the buffer capacitor $\mathrm{Cb}$. Energy recovery is achieved by discharging $\mathrm{Cb}$ to the output. Snubber operation principles

discussed for a boost converter can be extended to other topologies. Six basic nonisolated PWM dc/dc converters : Buck, Boost, Buck-boost, Cúk, Sepic and Zeta with the proposed snubbers embedded are shown in Fig. 6.

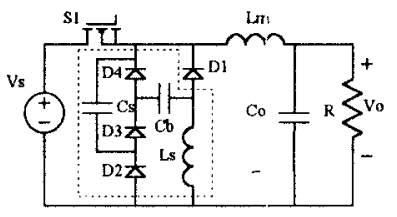

(a) Buck converter with snubber.

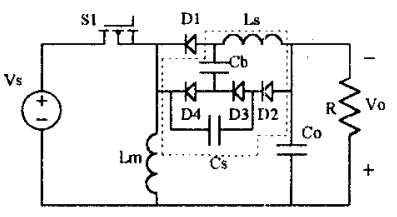

(c) Buck-boost converter with snubber.

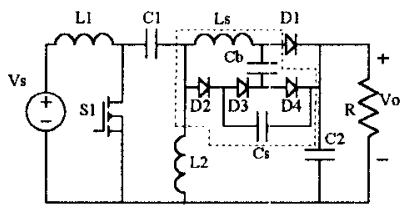

(e) Sepic converter with snubber

Fig 6. Six basic nonisolated PWM de/de converters with the proposed snubbers.

\section{EXPERIMENTAL RESULTS}

A prototype of $1 \mathrm{~kW}, 100 \mathrm{kHz}, 400 \mathrm{~V} \mathrm{DC}$ output boost converter with the passive lossless snubber has been built to verify the principle of operation and the theoretical analysis The components specifications are listed in Table 1.

TABLE 1

PART LIST OF THE IMPLEMENTED PROTOTYPE POWER CIRCUIT.

\begin{tabular}{||c|c||c|c|}
\hline Part & Type & Part & Value \\
\hline S1 $_{1}$ & IRFP460 & $\mathrm{Ls}_{s}$ & $5 u \mathrm{H}$ \\
\hline $\mathrm{D}_{1}$ & HFA15TB60 & $\mathrm{C}_{s}$ & $3.3 \mathrm{nF}$ \\
\hline $\mathrm{D}_{2}$ & HFA15TB60 & $\mathrm{Cb}_{1}$ & $100 \mathrm{nF}$ \\
\hline $\mathrm{D}_{3}$ & HFA15TB60 & $\mathrm{Lm}_{\mathrm{m}}$ & $180 u \mathrm{H}$ \\
\hline $\mathrm{D}_{4}$ & HFA15TB60 & $\mathrm{C}_{\mathrm{o}}$ & $940 u \mathrm{~F}$ \\
\hline
\end{tabular}

Efficiency of $96 \%$ at $1 \mathrm{~kW}$ has been measured. The snubber inductor current, snubber capacitor voltage and buffer capacitor voltage waveforms are shown in Fig. 7. The commutation waveforms of the MOSFET and the freewheeling diode with the proposed snubber embedded are shown in Fig. 8 and Fig. 9, respectively. Waveforms of MOSFET without snubber are shown in Fig. 10. 


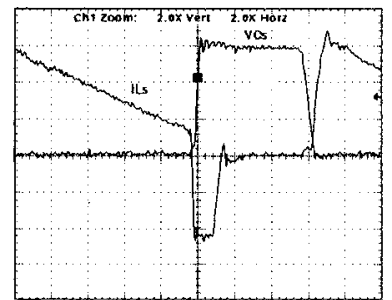

(a) Waveforms of $\mathrm{ILs}$ and $\mathrm{VCs}_{\mathrm{C}}$

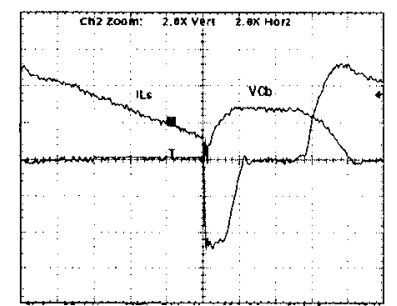

(b) Waveforms of ILs and $V_{C b}$
Fig 7. Waveforms of snubber inductor current ILs, snubber capacitor voltage $\mathrm{VCs}$ and buffer capacitor voltage $\mathrm{VCb}_{\mathrm{C}}$

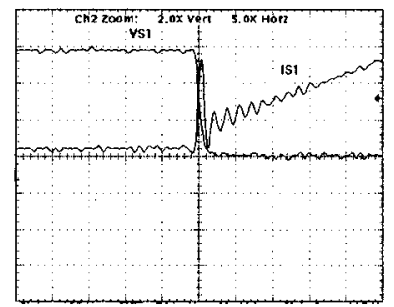

(a) Turn-on transients

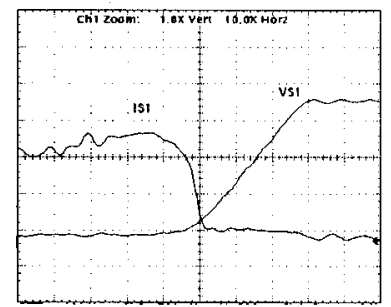

(b) Turn-off transients
Fig 8. Waveforms of MOSFET commutation with snubber

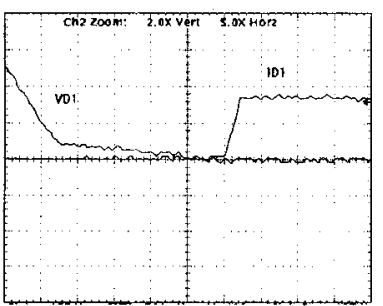

(a) Turn-on transients

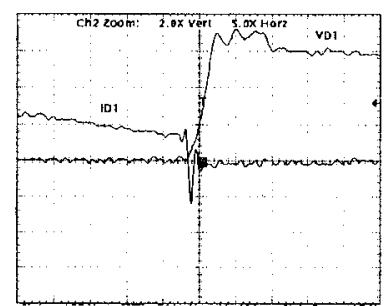

(b) Turn-off transients
Fig 9. Waveforms of freewheeling diode commutation with snubber.

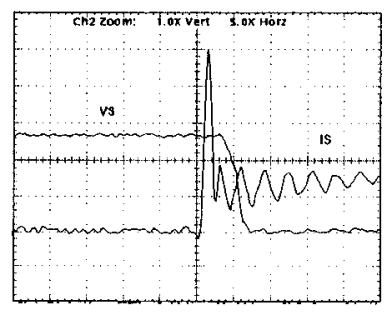

(a) Turn-on transients

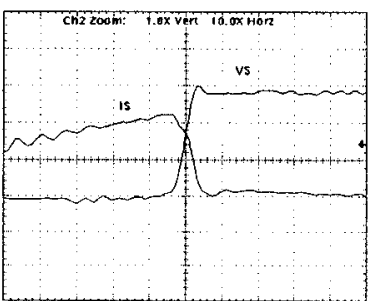

(b) Turn-off transients
Fig 10. Waveforms of MOSFET commutation without snubber.

Waveforms in Fig. 7(a) and Fig. 7(b) are exactly the same as predicted in Fig. 3. Snubber operation analysis is approved to be valid. Comparing Fig. 8(a) and Fig. 10(a), it can be seen that di/dt of drain current is restricted and commutation of the MOSFET is close to ZCS turn-on. The reason that the MOSFET operates only close to ZCS is the discharge of the parasitic drain-source capacitance of MOSFET during turn-on process. This switching loss can only be removed by resonant converter techniques or active snubbers. Comparing Fig. 8(b) and Fig. 10(b), it can also be seen that $\mathrm{dv} / \mathrm{dt}$ of drain-source voltage is restricted and the MOSFET commutates at ZVS turn-off. It can be seen from
Fig. 9(a) and Fig. 9(b) that the freewheeling diode is also commutated at ZVS turn-on and turn-off. EMI noises are reduced due to slower $\mathrm{di} / \mathrm{dt}$ of drain current.

\section{CONCLUSION}

Passive lossless snubbers for PWM dc/dc converters are proposed in this paper. The general snubber cell is the combination of a turn-on snubber and a turn-off snubber. Energy recovery is achieved by passive components only. Component values of snubber inductor, snubber capacitor and buffer capacitor can be determined by the designing rules presented in this paper. Current stress of MOSFET and voltage stress of freewheeling diode are also presented clearly. A $1 \mathrm{~kW}, 100 \mathrm{kHz}$ prototype of boost converter equipped with the snubber has been implemented in the laboratory to verify the analyses above. Experimental waveforms show that the growth rates of the reverse recovery current and drain-source voltage are successfully restricted by the snubber. The MOSFET operates at ZVS turn-off and close to ZCS turn-on, the freewheeling diode operates at ZVS turn-on and turn-off.

\section{REFERENCES}

[1] A. Pietkiewicz and D. Tollik, "Snubber circuit and mosfet paralleling considerations for high power boost-based power-factor correctors," INTELEC'95, pp. 41-45.

[2] A. Elasser and D. A. Torry, "Soft switching active snubbers for $\mathrm{dc} / \mathrm{dc}$ converters," IEEE Trans. Power Electron., vol. 11, no. 5, pp. 710-722, Sep. 1996.

[3] G. Hua and F. C. Lee, "Soft-switching techniques in PWM converters," IEEE Trans. Ind. Electron., vol. 42, no. 6, pp. 595-603, Dec. 1995.

[4] R. L. Lin and F. C. Lee, "Novel zero-current-switching-zero-voltageswitching converters," PESC'96, pp. 438-442.

[5] R. Streit and D. Tollik, "High efficiency telecom rectifier using a novel soft-switched boost-based input current shaper," INTELEC'91, pp. 720726.

[6] S. J. Finney, B. W. Williams and T. C. Green, "The RCD snubber revisited," IAS'93, pp. 1267-1273.

[7] G. A. Karvelis and S. N. Manias, "Fixed-frequency buck-boost zerovoltage-switched quasiresonant converter," IEE Proc. Electr. Power Appl., vol. 142, no. 5, pp. 289-296, Sèp. 1995.

[8] W. Gu and K. Harada, "A novel self-excited forward dc-dc converter with zero-voltage-switched resonant transitions using saturable core," IEEE Trans. Power Electron., vol. 10, no. 2, pp. 131-141, March. 1995.

[9] M. Ferranti, P. Ferraris, A. Fratta and F. Profumo, "Solar energy supply system for induction motors and various loads," INTELEC'89, paper 15.7 .

[10] N. Mohan, T. Undeland and W. Robbins, Power Electronics: Converters, Applications and Design. Wiley, 1989, pp. 462-467. 